\title{
Dynamic mechanical thermal analysis of aqueous sugar solutions containing fructose, glucose, sucrose, maltose and lactose
}

\author{
Isabel B. Cruz, ${ }^{1}$ Jorge C. Oliveira ${ }^{2} *$ \& William M. MacInnes ${ }^{3}$ \\ 1 Escola Superior de Biotecnologia, Universidade Católica Portuguesa, Rua Dr António Bernardino de Almeida, \\ 4200-Porto, Portugal \\ 2 Department of Food Science and Technology, University College Cork, Cork, Ireland \\ 3 Nestlé, Lausanne Research Centre, CH 1000 Lausanne 26, Switzerland
}

Summary The glass transition of glucose, fructose, lactose, maltose and sucrose solutions at maximum cryo-concentration was studied by Dynamic Mechanical Thermal Analysis (DMTA), using the disc bending technique. The glass transition temperatures were determined from the peaks in the loss modulus $E^{\prime \prime}$, which corresponds theoretically to the resonance point (Maxwell model) for several input frequencies. The frequency dependence was well described by both an Arrhenius-type model and by the WLF (Williams, Landel and Ferry) equation, yielding glass transition temperatures for an average molecular vibration time of $100 \mathrm{~s}$, which were similar to published midpoint temperatures determined by DSC scans. Some sugar mixtures were studied, yielding results that were well described by the Gordon-Taylor equation, using literature data. The frequency dependence of the viscoelastic ratio was also well approximated by an Arrhenius-type equation, with activation energies similar to those of the glass transition temperature and corresponded well to published values of the endset of glass transition.

Keywords Biomaterials science, frequency-response analysis, glass transition, molecular mobility, WLF equation.

\section{Introduction}

According to the Ehrenfest (1933) classification, glass transition has the properties of a second order phase transition that occurs over a temperature range, in which an amorphous glassy material (rigid and brittle) is transformed to a rubbery viscous liquid state (soft and flexible). This phenomenon is found in amorphous or semi-amorphous biopolymer matrices, which is the case for most concentrated food products.

Molecular mobility increases significantly above the glass transition, with important implications for the physical and chemical stability of foods (e.g. microbial growth, crystallization and recrys-

*Correspondent: Fax: 35321 4276398;

e-mail: j.oliveira@ucc.ie tallization, collapse of dried structures; Slade \& Levine, 1991). The glass transition is conventionally identified by a single temperature, designated glass transition temperature $\left(T_{\mathrm{g}}\right)$. It is usually identified from DSC scans, but there is some controversy in the literature as to what $T_{\mathrm{g}}$ should stand for: onset, endset or midpoint, as will be discussed later in the text. The standard for pure components, which is the intercept of the two asymptotes of the variation of a property such as entropy or volume with temperature (Scherer, 1991), has not been generally applied to foods and complex matrices in general.

One of the most important applications of this concept concerns food stability studies, as the reaction/decay rates of many quality/safety factors are found to be well related to molecular mobility and hence to glass transition (Slade 
\& Levine, 1993). Most foods are in a rubbery or liquid state and can reach glassy state on cooling or water removal. On glass transition, the molecular conformation of a rubbery amorphous matrix reaches its lower limiting entropy (or close to zero free volume - Doolittle, 1951). The average molecular vibration time of the matrix increases drastically as the glass transition is approached and the molecular mobility decreases. In the glassy state, matrices show only molecular vibration and muta-rotation, with viscosity in the region of $10^{12} \mathrm{~Pa} \mathrm{~s}$, and hence have a great stability.

The average molecular relaxation times of supercooled liquids above the glass transition have been shown to follow generally the empirical Vogel law (Mansfield, 1993), which can be directly transformed into the more usual empirical equation applied in biomaterials science (Slade \& Levine, 1993), the WLF (Williams, Landel and Ferry) equation (Williams et al., 1955; Mansfield, 1993):

$$
-\log \left(\frac{\tau}{\tau_{\mathrm{g}}}\right)=\frac{C_{1}\left(T-T_{\mathrm{g}}\right)}{C_{2}+T-T_{\mathrm{g}}}
$$

where log stands for decimal logarithm (base $10), \tau$ is the average molecular vibration time at temperature $T$, and $\tau_{\mathrm{g}}$ the respective value at $T_{\mathrm{g}}$. $C_{1}$ and $C_{2}$ are model parameters. $C_{1}$ would be, in principle, the difference in order of magnitude between the average atomic vibration time $\left(c .10^{-13} \mathrm{~s}\right)$ and the average molecular vibration time in the glassy state $\left(c .10^{3} \mathrm{~s}\right)$, that is, around 16. Williams et al. (1955) proposed the universal values of 17.44 for $C_{1}$ and $51.6{ }^{\circ} \mathrm{C}$ for $C_{2}$ by fitting data from many polymers. However, some authors have cautioned against the use of universal constants, as specific systems may show quite a variation (Mansfield, 1993). Peleg (1992) collected $C_{1}$ values from the literature ranging from 13.7 to 34 and $C_{2}$ values between 24 and $80{ }^{\circ} \mathrm{C}$, although even lower $C_{1}$ values were collected by Roos (1995). From the comprehensive work of Angell et al. (1994), it is clear that while $C_{1}$ could indeed be a universal constant with a value around $16, C_{2}$ is a systemdependent value and should be determined for the specific matrix in question.

The Arrhenius equation has also been applied with success in a number of cases:

$$
-\log \left(\frac{\tau}{\tau_{\mathrm{g}}}\right)=\frac{E_{\mathrm{a}}}{R}\left(\frac{1}{T}-\frac{1}{T_{\mathrm{g}}}\right)
$$

where ln stands for natural logarithm (base e), $E_{\mathrm{a}}$ is the activation energy and $R$ the ideal gas constant $\left(8.314 \mathrm{~J} \mathrm{~mol}^{-1} \mathrm{~K}^{-1}\right)$. As shown by Angell et al. (1991, 1994), systems designated as 'strong' (as opposed to 'fragile') would show a behaviour close to the Arrhenius model, even around the glass transition (these are liquids with high resistance to thermal degradation). However, this is not the case for most food systems, which would show a break in the Arrhenius plot (MacInnes, 1993). Nevertheless, the Arrhenius equation might still give reasonable results in a sufficiently small temperature range, on either side of such a breakpoint. It is particularly noteworthy that in the vicinity of the glass transition, in the rubbery state, viscosity can be described by the so-called Adam-Gibbs equation, developed from a thermodynamic approach proposed by Adam \& Gibbs (1965), which can be reduced to the simple Arrhenius form. Hence, there would be a sound theoretical foundation for using an Arrhenius-type equation close to the glass transition.

The difference between WLF or Arrhenius models can be ultimately related to the viscosity model that one is inherently assuming (as the average relaxation time and the viscosity are proportional): following the free volume theory of molecular mobility (Cohen \& Turnbull, 1959) one obtains the VTF (Vogel, Tamman and Fulcher) equation, which is interconvertible with the WLF model (Angell et al., 1994), while if one assumes an isostructural viscosity model, the Arrhenius equation is obtained (Scherer, 1991).

There is quite a lot of physical evidence for many liquids showing that the value of $\tau_{\mathrm{g}}$ is around $100-1000 \mathrm{~s}$, and mostly close to $200 \mathrm{~s}$ (Angell et al., 1991), but this cannot be generalized to complex food matrices without further experimental verification. Fixing the value of $\tau_{\mathrm{g}}$ at $100 \mathrm{~s}$ has been used by Moynihan et al. (1971) and Angell et al. (1994).

Diffusion-dependent phenomena can also be expected to follow a WLF model, given the relationship between viscosity and diffusivity. Thus, the WLF equation has been successfully applied to microbial death and quality decay rates, 
showing particularly better fits than the Arrhenius equation as the glass transition is approached (Slade \& Levine, 1993; Kerr et al., 1993).

Therefore, it could be argued that a useful indicator for $T_{\mathrm{g}}$ should be the parameter that corresponds to the WLF equation (1), particularly for stability studies, where the WLF equation, in the above or a modified form, would be used to describe the influence of temperature and water content on reaction rates.

The water content dependency results from the plasticizing effect of water, as $T_{\mathrm{g}}$ decreases significantly with water content (Slade \& Levine, 1991). This effect has been successfully described, particularly in binary mixtures, by the Gordon-Taylor equation (Gordon \& Taylor, 1952):

$$
T_{\mathrm{g}}=\frac{k w T_{\mathrm{g}(\text { water })}+(1-w) T_{\mathrm{g}(\text { dry matrix })}}{k w T_{\mathrm{g}}+(1-w)}
$$

where $w$ is the water content (in $g_{\text {water/ }}$ $g_{\text {water }+ \text { solid }}$, and $k$ is a system parameter, to be obtained from model fitting of experimental data for several water contents. This is in fact a derivation of the theoretically based CouchmanKarasz equation (Couchman, 1978), with the empirical parameter $k$ replacing the ratio of the specific heat increase for water, because of the glass transition, and that for the dry matrix. Although the equation becomes empirical, the added flexibility allows for a wider application. With the empirical constant $k$ determined by data regression, the equation has been applied with success to several food systems (Roos \& Karel, 1991; Roos, 1995; Frias et al., 1998), with $k$ values ranging roughly between 2 and 10 .

For aqueous solutions below the maximum cryo-concentration (that is, the concentration above which no ice crystallization is possible and the solution vitrifies), as the solution cools below the freezing point, it cryo-concentrates as ice crystals are formed and the freezing temperature of the cryo-concentrated solution decreases while its glass transition temperature increases. The value of $T_{\mathrm{g}}$ for the maximally freeze-concentrated solution is denoted $T_{\mathrm{g}}^{\prime}$, and the corresponding concentration $C_{\mathrm{g}}^{\prime}$, while the freezing/melting temperature is $T_{\mathrm{m}}^{\prime}$. Whether $T_{\mathrm{g}}^{\prime}$ and $T_{\mathrm{m}}^{\prime}$ are equal, or the former is lower, is a debatable issue (a good discussion is provided by Slade \& Levine, 1995), but evidently, the endset of the glass transition should be roughly equal to $T_{\mathrm{m}}^{\prime}$, whatever the definitions used.

The determination of $T_{\mathrm{g}}$ according to equation (1) can be made rather straightforwardly by Dynamic Mechanical Thermal Analysis (DMTA).

The objective of this work was to apply DMTA measurements and compare the results with literature data, thereby establishing the usefulness of DMTA for obtaining objective indicators of the glass transition, suitable for stability studies of frozen food matrices. Sugar solutions, which are among the most widely reported (model) food systems in published studies, were used.

\section{Glass transition analysis by DMTA}

Dynamic Mechanical Thermal Analysis is a frequency-response test, which can be theoretically interpreted in terms of system dynamics theory, well known in process engineering (Luyben, 1990).

The DMTA measures the rheological properties of a system continuously, while the temperature is changed, usually by linear increase or decrease scans. The rheological measurements are normally made by compression or bending tests, which quantify the modulus of elasticity of the matrix by measuring the stress caused by a given input strain.

The concept of dynamic or frequency-response tests is to cause a sinusoidal input strain. It is fairly simple to demonstrate theoretically that in the linear viscoelastic range the response of any stable system will tend to an output sinusoidal stress that has the same frequency as the input strain (Luyben, 1990), although with a phase angle, which can vary from $0^{\circ}$ for an ideal solid body to $90^{\circ}$ for an ideal liquid (Darby, 1975). Furthermore, it can also be demonstrated that in the linear viscoelastic range, the phase angle $(\delta)$ and the ratio of the amplitudes of the output and input sinusoidal waves, which are independent of the amplitude of the input wave, allow for the quantification of the fraction of mechanical energy input which is stored (elastic behaviour) and the fraction which is dissipated (plastic behaviour). The relationships between the measuring and system variables are the following: Input strain wave $\quad \varepsilon=\varepsilon_{0} \sin (\omega t)$ Output stress wave $\quad \sigma=\sigma_{0} \sin (\omega t+\delta)$ Complex elastic modulus $E^{*}=E^{\prime}+\mathrm{i} E^{\prime \prime}$;

$$
\begin{aligned}
& \left|E^{*}\right|=\sigma_{0} / \varepsilon_{0} \\
& \quad=\left(E^{\prime 2}+E^{\prime \prime 2}\right)^{1 / 2}
\end{aligned}
$$


Storage modulus

Loss modulus

Phase angle

$E^{\prime}=\left|E^{*}\right| \cos \delta$

$E^{\prime \prime}=\left|E^{*}\right| \sin \delta$

$\tan \delta=E^{\prime \prime} / E^{\prime}$

where $\varepsilon$ is the strain at time $t, \varepsilon_{0}$ the strain amplitude, $\sigma$ the stress at time $t, \sigma_{0}$ the stress amplitude, $\omega$ the frequency, $\delta$ the phase angle $\left(\tan \delta\right.$ is the visco-elastic ratio), $E^{*}$ the complex elastic modulus, $E^{\prime}$ the storage elastic modulus (mechanical energy storage), $E^{\prime \prime}$ the loss elastic modulus (mechanical energy dissipation) and $i$ is the imaginary unit (square root of -1 ). $E^{*}$ is the system transfer function in the frequency-response domain. Thus, it can be easily demonstrated that for a first-order system (e.g. the Maxwell model of viscoelasticity), the maximum loss modulus $E^{\prime \prime}$ (maximum of energy dissipation) occurs when the input frequency and the system frequency (reciprocal of the average relaxation time) are in resonance (Luyben, 1990; Allen, 1993).

Therefore, the peak of the $E^{\prime \prime}$ vs. temperature plot for a given frequency will indicate the temperature at which the average molecular relaxation time of the matrix is the reciprocal of the input frequency. Measurements at different frequencies should therefore allow one to apply equation (1) in order to estimate $T_{\mathrm{g}}$. Arrhenius plots can also be constructed. MacInnes (1993) found the breakpoint in the Arrhenius plot at frequencies around $20 \mathrm{~Hz}$ for sucrose solutions; at lower frequencies an Arrhenius model with high activation energy fitted the data well.

Other features of the glass transition can also be identified with the DMTA results. As in the glassy state, $E^{\prime}$ is relatively unaffected by temperature, the onset of the glass transition corresponds to an initial drop in the $E^{\prime}$ vs. $T$ plot. The end of the glass transition would occur at a point where $E^{\prime}$ becomes less sensitive to temperature again (having fallen by $2-3$ orders of magnitude), and thus could be identified by a peak in the $\tan \delta$ plot. If solute crystallization occurs, the patterns can be greatly affected in this region.

\section{Materials and methods}

\section{Materials}

Binary systems of water + sucrose, fructose, lactose, maltose or glucose were prepared with $30 \%$ $\left(\mathrm{g}_{\text {solid }} / \mathrm{g}_{\mathrm{water}}+\right.$ solid $)$ total solids. Equal proportions of the solutes were used to produce ternary and quaternary solutions of water + (fructose + glucose), (fructose + lactose), (glucose + lactose), (glucose + maltose) or (fructose + glucose + lactose), so that the final solids concentration was also $30 \%$. Bi-distilled water and sugars of analytical purity (Merck, Whitehouse station, NJ, USA) were used to make the solutions.

\section{Methods}

A DMTA unit (RSAII, Rheometrics, Piscataway, NJ, USA), equipped with a disc-bending sample holder specially constructed for this purpose (Fig. 1), was used to measure the viscoelastic properties.

The upper and lower rings of the sample holder clamp two plastic discs and the centering ring, and were rigidly attached to the DMTA. The bottom shaft that causes the sinusoidal strain operates the rings, and the upper shaft, where the stress is measured, is attached to the centre of the sample holder. The liquid samples were injected into the space between the plastic discs, through a $1.2 \mathrm{~mm}$ diameter hole in the centering ring (Fig. 1).

The centre of the disc was subjected to an oscillatory small-amplitude deflection (strain amplitude $0.001 \mathrm{~m}$ ) by the DMTA drive shaft, and the corresponding stress measurements were made at several frequencies with a frequency sweep test. The following multi-wave frequency programmes were used: $0.2,0.4,0.8,1.6,3.2,6.4,12.8$ and 0.1 , $1.0,10 \mathrm{~Hz}$. In such tests, the equipment measures the same sample at the different programmed

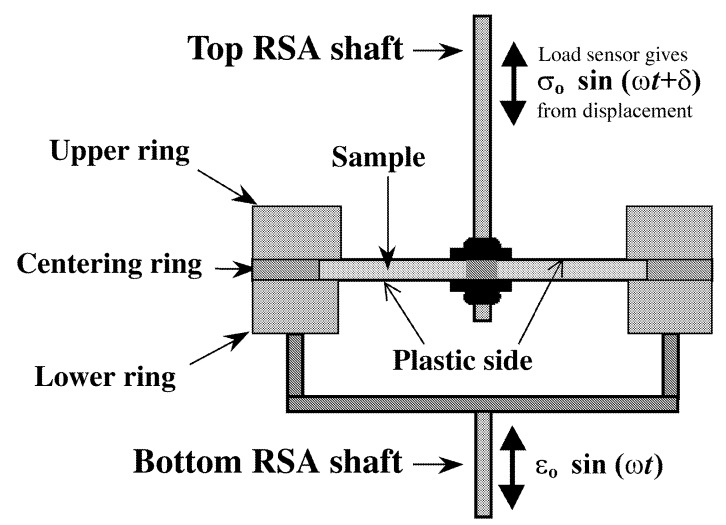

Figure 1 Sketch of the DMTA tool designed for analysing aqueous solutions in a Rheometrics DMTA. 
frequencies at each temperature step. Preliminary experiments were made to verify that such a procedure yielded similar results to taking one frequency measurement at a time. Between two and three replicates were made (except for maltose, which was not replicated).

The sample temperature was measured with a thermocouple located inside the sample. Temperature was scanned, at $0.4^{\circ} \mathrm{C} \mathrm{min}{ }^{-1}$ by the DMTA temperature controller, from -70 to $0{ }^{\circ} \mathrm{C}$.

Data regressions were performed, with Excel software (Excel 97, Microsoft, Seattle, WA, USA) and KaleidaGraph software (KaleidaGraph 3.0, Synergy Software, Reading, PA, USA), on the equations obtained by manipulating equation (1) or (2) to yield $T$ vs. $\omega$, as the former is the measured response and the latter the input factor.

\section{Results and discussion}

Some preliminary scans were made with the binary solutions at different heating rates from 0.3 to $1.2{ }^{\circ} \mathrm{C} \mathrm{min}{ }^{-1}$. No significant differences were found below $0.8{ }^{\circ} \mathrm{C} \mathrm{min}{ }^{-1}$, with 1 and $1.2{ }^{\circ} \mathrm{C} \min ^{-1}$ showing a consistent tendency to yield significantly higher peak temperatures. Various heating and cooling (from 0 to $-70{ }^{\circ} \mathrm{C}$ ) scans with the same sample were also performed. It was clear that if cooling was sufficiently fast to avoid crystallization, the scans were perfectly reversible. However, there was a significant difference in the peak temperatures between heating and cooling scans for all solutions, with the peak temperatures for cooling scans being around $2-5{ }^{\circ} \mathrm{C}$ lower than those for the heating scans. The variation of $T_{\mathrm{g}}$ with the heating rate and the existence of hysteresis (the measurements follow a different path in heating than they do in cooling) stem from the nonexponential nature of structural relaxation, and suitable theories exist to describe these influences (Scherer, 1991) attention is drawn to Narayanaswamy's work (1971). However, as this is outside the scope of the present work, it was decided to use sufficiently low heating rates to have a negligible effect of this parameter on the measurements and to analyse only the data from heating scans.

A typical DMTA response is shown in Fig. 2, where the influence of the frequency can be well observed. The glass transition is a second-order phase transition and, as such, is influenced by
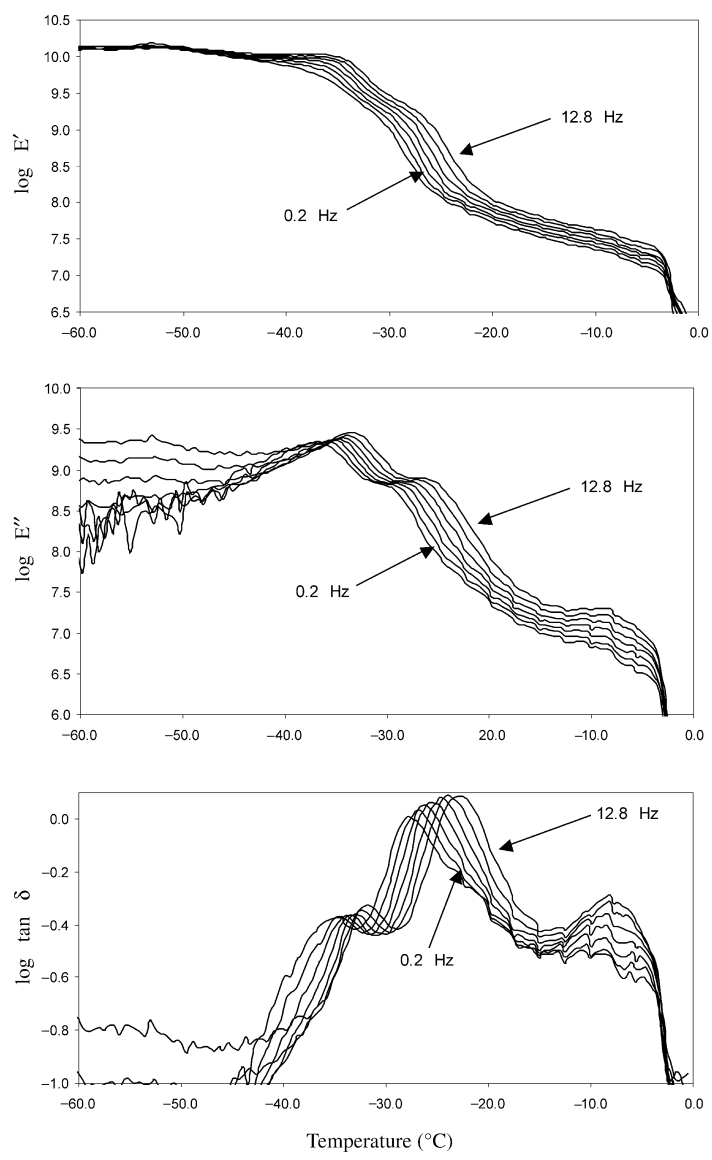

Figure 2 Typical DMTA thermograms (glucose). Curves from left to right indicate the system response for the frequencies of $0.2,0.4,0.8,1.6,3.2,6.4$ and $12.8 \mathrm{~Hz}$.

frequency, while changes caused by first-order transitions (such as crystallization) should be frequency-independent. Thus, it is clear that the peaks in $\tan \delta$ are indicators of the end of the glass transition and not of $T_{\mathrm{m}}^{\prime}$.

Figure 3a-e show the plots of the WLF equation for the binary water-sugar matrices. It may be noted from manipulation of equation (1) that, with these co-ordinates, the WLF model is not a straight line, but slightly curved, tending to a straight line as $T$ approaches $T_{\mathrm{g}}^{\prime}$ and $\tau / \tau_{\mathrm{g}}$ tends to unity. The values of $T_{\mathrm{g}}^{\prime}$, assuming the relaxation time at the glassy state $\left(\tau_{\mathrm{g}}\right)$ to be 100 or $1000 \mathrm{~s}$, are indicated as dashed horizontal lines. As can be seen, the value measured at $0.1 \mathrm{~Hz}$ is an outlier point in most of the graphs (which was, therefore, not used in the fits). This may be because of the 

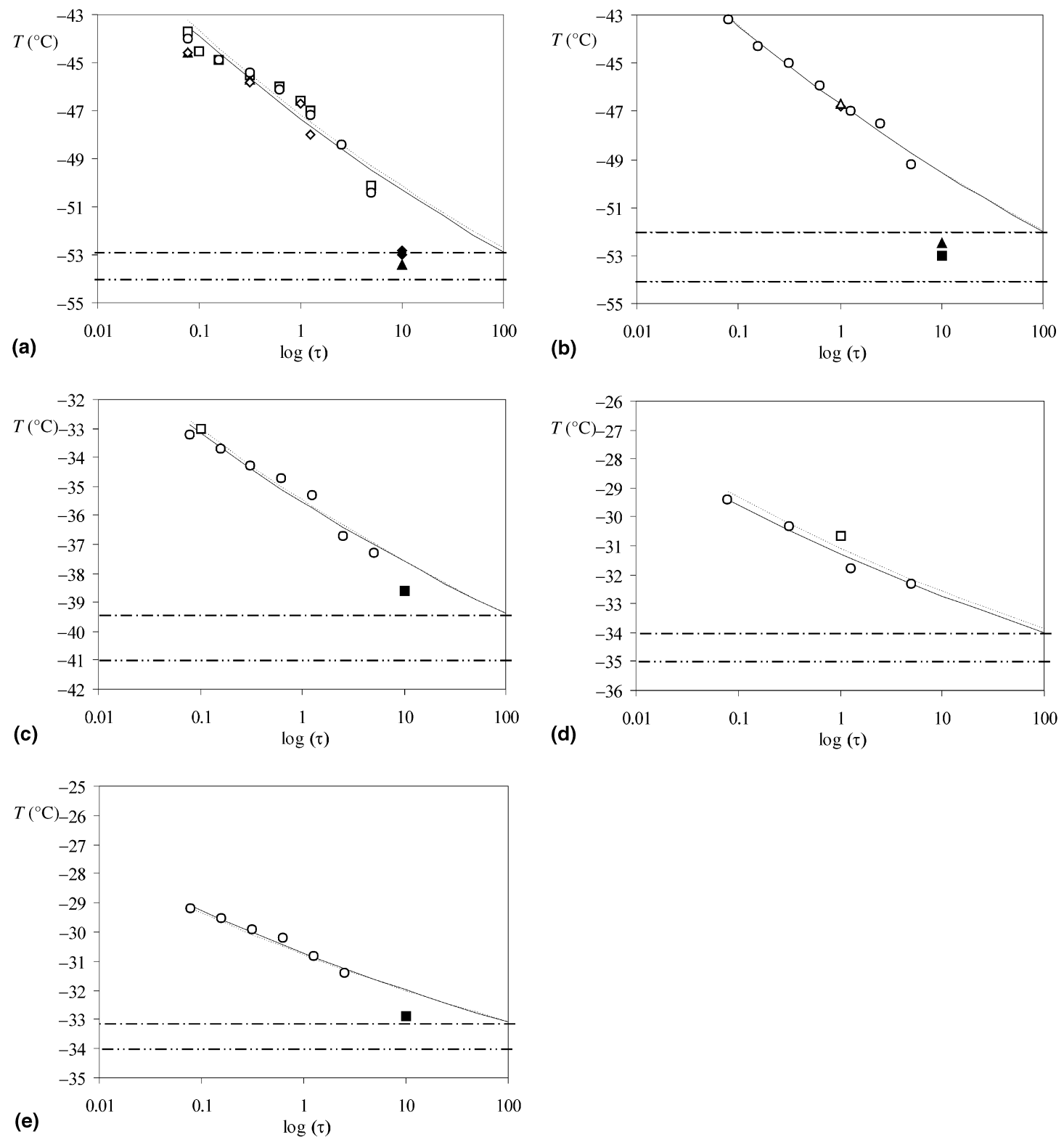

Figure 3 WLF plots of the $\mathrm{E}^{\prime \prime}$ peak temperatures and model fit for $\mathrm{C}_{1}=16$ and $\tau_{\mathrm{g}}=100 \mathrm{~s}$ (solid line) or $\tau_{\mathrm{g}}=1000 \mathrm{~s}$ (dashed line) for binary (water-sugar) matrices. Open symbols indicate points used in the model regression, while closed symbols were considered outliers. Different symbols correspond to replicate samples. The top horizontal dashed line indicates the $T_{g}^{\prime}$ estimated by the model regression for $\tau_{\mathrm{g}}=100 \mathrm{~s}$ (solid line), and the bottom horizontal line the $\mathrm{T}_{\mathrm{g}}^{\prime}$ for $\tau_{\mathrm{g}}=1000 \mathrm{~s}$. (a) fructose; (b) glucose; (c) sucrose; (d) maltose; (e) lactose.

equipment precision, as the temperature at that frequency is already close to $T_{\mathrm{g}}^{\prime}$ (it can be seen in Fig. 2 that as the frequency decreases, the peak in $E^{\prime \prime}$ becomes more imperceptible). However, the impact of the $\tau_{\mathrm{g}}$ value is small, as in the range of interest $(100-1000 \mathrm{~s})$, the resulting $T_{\mathrm{g}}^{\prime}$ varies generally by $<2{ }^{\circ} \mathrm{C}$. Figure 4 shows the pooled data for the sugar mixtures tested. The WLF parameters obtained by fixing $C_{1}$ at 16 and $\tau_{\mathrm{g}}$ at 100 or $1000 \mathrm{~s}$ are shown in Table 1. 


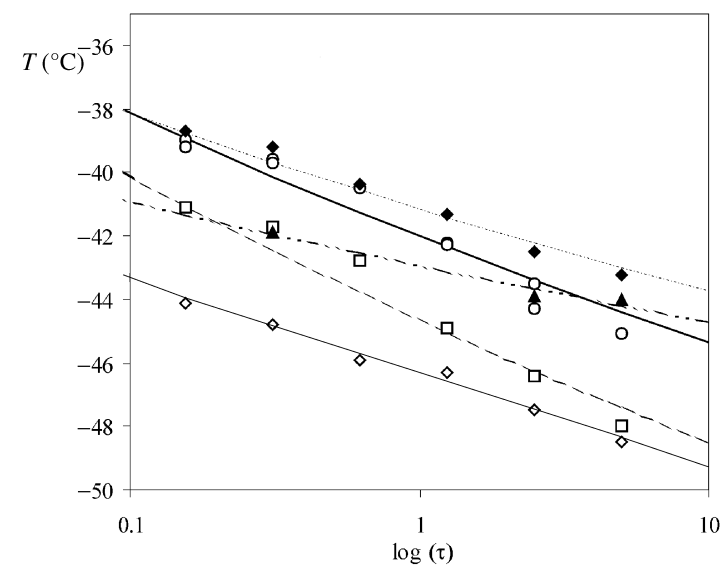

Figure 4 The WLF plots of the $\mathrm{E}^{\prime \prime}$ peak temperatures and model fit for $\mathrm{C}_{1}=16$ and $\tau_{\mathrm{g}}=100 \mathrm{~s}$ for sugar mixtures. $\bigcirc$ : fructose + lactose; $\diamond$ : glucose + fructose;

glucose + lactose; $\boldsymbol{\Lambda}$ : glucose + maltose; $\square$ : gluc. + fruct. + lact.

The Arrhenius equation could also be fitted to the data with similar success, in agreement with the findings of MacInnes (1993) for sucrose, as all frequencies were below $20 \mathrm{~Hz}$. Again, the lower point at $0.1 \mathrm{~Hz}$ is generally an outlier. Figure 5 shows the Arrhenius plots for the $\mathrm{E}^{\prime \prime}$ peak temperatures, and Fig. 6 those of the peak $\tan \delta$ temperatures for the binary water-sugar matrixes. The Arrhenius parameters are shown in Table 2.

It is interesting to note that the activation energies of the binary water sugar matrices for the $E^{\prime \prime}$ peak temperatures are not statistically different from those for the peak tan $\delta$ temperatures. This is another indication that $\tan \delta$ peaks may be taken as measurements of the endset of the glass transition. However, curiously, this cannot be said for all the sugar mixtures.

It is noteworthy that for the binary water-sugar matrices, $C_{2}$ decreases with increasing $T_{\mathrm{g}}^{\prime}$ (inversely, $E_{\mathrm{a}}$ increases with $T_{\mathrm{g}}^{\prime}$ in the Arrhenius model). This indicates that generally, the sugars with higher $T_{\mathrm{g}}^{\prime}$ showed a higher sensitivity to temperature. Such a relationship was not clear in the sugar mixtures.

It is important to compare the values obtained here with those reported in the literature. Because of the application of slightly different concepts and nomenclature, there is some confusion in data collected from the literature; some authors indicate $T_{\mathrm{g}}$ as the onset temperature, others as the midpoint, still others as the endset, or close to the endset; some authors designate a $T_{\mathrm{m}}^{\prime}$ that is above $T_{\mathrm{g}}^{\prime}$ and maybe even above the endset of the glass transition, while others say that $T_{\mathrm{m}}^{\prime}$ is no more than the end of the glass transition. An emerging consensus points to the use of $T_{\mathrm{m}}^{\prime}$ as $T_{\mathrm{g}}^{\prime}$, the critical temperature below which a food matrix is stable, regardless of whether this does indeed correspond to a glass transition parameter or not (Slade \& Levine, 1995). The most relevant data collected from the literature are shown in Table 3. The data were pooled according to their overall consistency - some authors (e.g. Slade \& Levine, 1991) designated simply as $T_{\mathrm{g}}^{\prime}$ values which were included in Table 3 as endset, by comparison with the results of other authors that distinguished between onset, midpoint and endset or $T_{\mathrm{m}}^{\prime}$. It is evident that there is no significant difference between $T_{\mathrm{m}}^{\prime}$ and endset of the glass transition. The authors who distinguished between endset and $T_{\mathrm{m}}^{\prime}$ obtained values for the latter that are
Table 1 Glass transition temperature $\left(T_{\mathrm{g}}^{\prime}\right)$ and system constant $C_{2}$ for maximally freezeconcentrated aqueous solutions (obtained by WLF fitting)

\begin{tabular}{|c|c|c|c|c|}
\hline Solids & $\begin{array}{l}C_{2} \\
\tau_{g}=100 \mathrm{~s}\end{array}$ & $\begin{array}{l}C_{2} \\
\tau_{g}=1000 \mathrm{~s}\end{array}$ & $\begin{array}{l}T_{\mathrm{g}}^{\prime}\left({ }^{\circ} \mathrm{C}\right) \\
\tau_{\mathrm{g}}=100 \mathrm{~s}\end{array}$ & $\begin{array}{l}T_{g}^{\prime}\left({ }^{\circ} \mathrm{C}\right) \\
\tau_{g}=1000 \mathrm{~s}\end{array}$ \\
\hline Fructose & $39 \pm 5$ & $34 \pm 4$ & $-52.9 \pm 0.8$ & $-55.0 \pm 0.9$ \\
\hline Glucose & $37 \pm 2$ & $32 \pm 2$ & $-52.0 \pm 0.3$ & $-54.1 \pm 0.4$ \\
\hline Sucrose & $27 \pm 2$ & $24 \pm 2$ & $-39.4 \pm 0.4$ & $-41.0 \pm 0.5$ \\
\hline Maltose & $19 \pm 4$ & $17 \pm 3$ & $-34.0 \pm 0.6$ & $-35.0 \pm 0.8$ \\
\hline Lactose & $17 \pm 2$ & $14 \pm 1$ & $-33.1 \pm 0.3$ & $-34.0 \pm 0.4$ \\
\hline Glucose $50 \%$-Fructose $50 \%$ & $35 \pm 2$ & $28 \pm 2$ & $-51.4 \pm 0.4$ & $-52.8 \pm 0.5$ \\
\hline Glucose $50 \%$-Lactose $50 \%$ & $34 \pm 3$ & $29 \pm 2$ & $-46.0 \pm 0.5$ & $-47.9 \pm 0.6$ \\
\hline Fructose $50 \%$-Lactose $50 \%$ & $44 \pm 4$ & $38 \pm 3$ & $-48.3 \pm 0.6$ & $-50.8 \pm 0.8$ \\
\hline Glucose $50 \%$-Maltose $50 \%$ & $23 \pm 2$ & $20 \pm 2$ & $-46.2 \pm 0.3$ & $-47.5 \pm 0.4$ \\
\hline $\begin{array}{c}\text { Glucose } 33 \% \text {-Fructose } \\
33 \% \text {-Lactose } 33 \%\end{array}$ & $51 \pm 5$ & $44 \pm 5$ & $-51.9 \pm 0.9$ & $-55 \pm 1$ \\
\hline
\end{tabular}




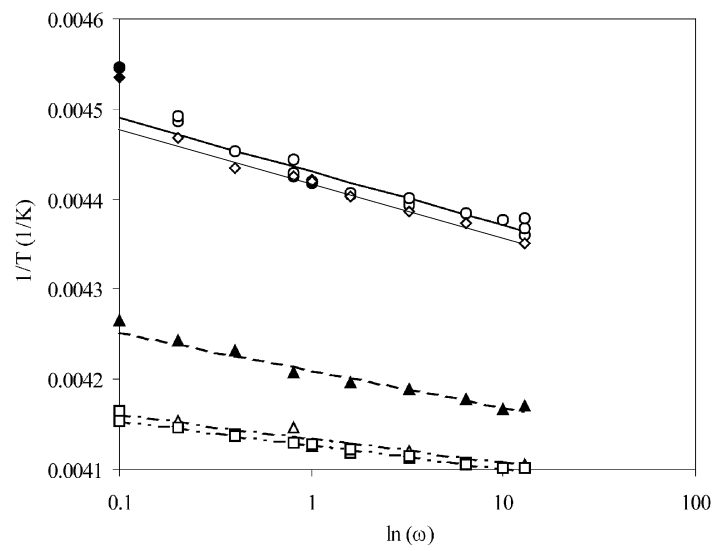

Figure 5 Arrhenius plots of the $\mathrm{E}^{\prime \prime}$ peak temperatures for the binary (water-sugar) matrices. Closed symbols indicate outliers. $\bigcirc$ : fructose; $\diamond$ : glucose; $\boldsymbol{\Delta}$ : sucrose; $\triangle$ : maltose; $\square$ : lactose.

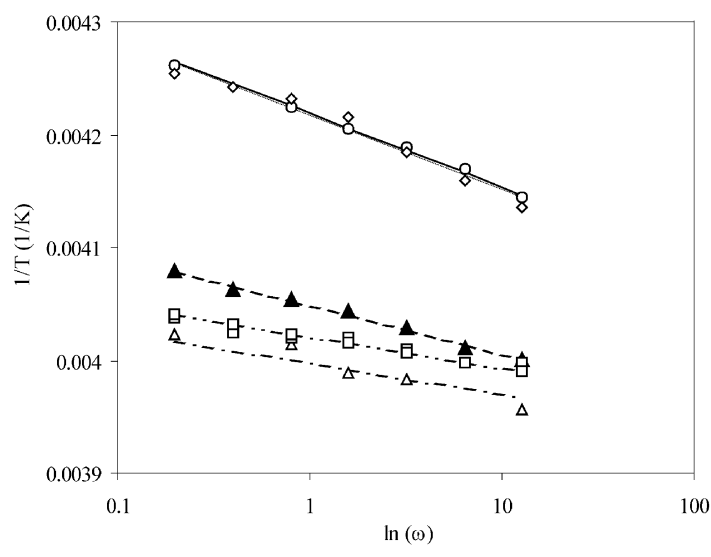

Figure 6 Arrhenius plots of the tan $\delta$ peak temperatures for the binary (water-sugar) matrices. $\bigcirc$ : fructose; $\diamond$ : glucose; $\Delta$ : sucrose; $\triangle$ : maltose; $\square$ : lactose.

close to what other authors indicated as endset of the glass transition. There is quite some variation among published data on the endset of the glass transition, reaching as much as $10{ }^{\circ} \mathrm{C}$, which is most likely because of not only the different measuring methods, but also the different ways of treating and interpreting the data, even when the method (mostly DSC) is the same.

The $T_{\mathrm{g}}^{\prime}$ values obtained in this work, whether from the WLF or Arrhenius models, with a relaxation time of $100 \mathrm{~s}$, are very close to the midpoint values in the existing literature (mostly from Roos, Karel and co-workers), being at least $2-3{ }^{\circ} \mathrm{C}$ lower than what some other authors designated as the glass transition temperature. The $\tan \delta$ peak temperature for a relaxation time of $100 \mathrm{~s}$ seems to be a good measurement of the endset of the glass transition, falling in the lower range of literature values shown in Table 3, close to those suggested by Slade \& Levine (1991), except for maltose, where the value obtained here is about $3{ }^{\circ} \mathrm{C}$ lower.

The results obtained for sugar mixtures permit an important test: the applicability of the GordonTaylor equation to predict the glass transition temperature of sugar mixtures, or to estimate $C_{\mathrm{g}}^{\prime}$, just like the WLF equation was used to estimate $T_{\mathrm{g}}^{\prime}$ from the DMTA data. This is an interesting option because the experimental determination of $C_{\mathrm{g}}^{\prime}$ is also complex and not at all straightforward, because of the difficulty in estimating accurately the exact amount of ice that exists at maximum cryo-concentration. Reid et al. (1993) have discussed this subject clearly and the limitations of existing methods. With a more correct approach, albeit based on a hypothetical procedure, they obtained values of $C_{\mathrm{g}}^{\prime}$ around $79-80 \%$, while earlier literature references suggested values around $53-65 \%$, because of an apparent underestimation of the ice content. It is important to note that if $C_{\mathrm{g}}^{\prime}$ is estimated from the value of concentration where $T_{\mathrm{g}}$ equals $T_{\mathrm{g}}^{\prime}$, combining the data presented by Roos \& Karel (1991) with those of Noel et al. (1996) (for maltose), Chan et al. (1986) (for glucose), Ablett et al. (1993a) (for fructose) and Roos (1995) (for sucrose), also yields $C_{\mathrm{g}}^{\prime}$ values around $79-81 \%$ for these sugars. Roos \& Karel (1993) also considered, from various studies, that the maximum cryo-concentration of sugar solutions is around $80 \%$. Values between 78 and $81 \%$ were reported for malto-oligomers by Ablett et al. (1993b).

By manipulation of equation (3), the maximum cryo-concentration for each solution can be determined from the glass transition temperatures of the pure sugars, water and the $k$ values. From the Couchman-Karasz concept, equation (3) could be generalized for ternary solutions, as

$$
T_{\mathrm{g}(i+j)}=\frac{w T_{\mathrm{g}(\text { water })}+x_{i}\left(T_{\mathrm{g} i} / k_{i}\right)+x_{j}\left(T_{\mathrm{g} i} / k_{j}\right)}{w+\left(x_{i} / k_{i}\right)+\left(x_{i} / k_{i}\right)}
$$

where $i$ and $j$ represent any two sugars, $x_{i}$ and $x_{j}$ are the mass fractions, $k_{i}$ and $k_{j}$ the GordonTaylor parameters of equation (3) for each sugar, 
Table 2 Arrhenius parameters of the average molecular relaxation times and $\tan \delta$ peaks for maximally freeze-concentrated sugar solutions

\begin{tabular}{|c|c|c|c|c|}
\hline Solids & $T_{\mathrm{p} 1}\left({ }^{\circ} \mathrm{C}\right)(\omega=1 \mathrm{~Hz})$ & $E_{\mathrm{ag}}\left(\mathrm{kJ} \mathrm{mol}^{-1} \times 0.1\right)$ & $T_{\delta 1}\left({ }^{\circ} \mathrm{C}\right)(\omega=1 \mathrm{~Hz})$ & $E_{\mathrm{a} \delta}\left(\mathrm{kJ} \mathrm{mol}^{-1} \times 0.1\right)$ \\
\hline Fructose & $-47.3 \pm 0.1$ & $33 \pm 2$ & $-35.9 \pm 0.1$ & $30 \pm 2$ \\
\hline Glucose & $-46.7 \pm 0.1$ & $31 \pm 1$ & $-35.9 \pm 0.1$ & $28 \pm 3$ \\
\hline Sucrose & $-35.5 \pm 0.1$ & $46 \pm 3$ & $-26.0 \pm 0.1$ & $44 \pm 4$ \\
\hline Maltose & $-31.2 \pm 0.2$ & $69 \pm 9$ & $-22.8 \pm 0.2$ & $68 \pm 8$ \\
\hline Lactose & $-30.7 \pm 0.1$ & $78 \pm 6$ & $-24.2 \pm 0.1$ & $70 \pm 8$ \\
\hline Glucose $50 \%$-Fructose $50 \%$ & $-46.4 \pm 0.1$ & $36 \pm 2$ & $-35.0 \pm 0.1$ & $36 \pm 2$ \\
\hline Glucose $50 \%$-Lactose $50 \%$ & $-41.1 \pm 0.1$ & $36 \pm 2$ & $-30.4 \pm 0.2$ & $39 \pm 3$ \\
\hline Fructose $50 \%$-Lactose $50 \%$ & $-42.0 \pm 0.2$ & $28 \pm 2$ & $-30.5 \pm 0.2$ & $40 \pm 4$ \\
\hline Glucose $50 \%-$ Maltose $50 \%$ & $-42.9 \pm 0.1$ & $53 \pm 5$ & $-32.2 \pm 0.3$ & $33 \pm 4$ \\
\hline $\begin{array}{l}\text { Glucose } 33 \%-\text {-Fructose } 33 \%- \\
\text { Lactose } 33 \%\end{array}$ & $-44.5 \pm 0.3$ & $23 \pm 2$ & $-32.4 \pm 0.3$ & $41 \pm 2$ \\
\hline
\end{tabular}

Manipulating equation (2), the Arrhenius model for the $E^{\prime \prime}$ peak temperatures is $\frac{1}{T}=\frac{1}{T_{p 1}}-\frac{R \ln \omega}{E_{a g}}$, where $T_{\mathrm{p} 1}$ is the $E^{\prime \prime}$ peak temperature at the input frequency of $1 \mathrm{~Hz}, E_{\text {ag }}$ is the activation energy, $R$ is the ideal gas constant and $\omega$ is the input frequency. Similarly, the Arrhenius model for the tan $\delta$ peak temperatures is $\frac{1}{T}=\frac{1}{T_{\delta 1}}-\frac{R \ln \omega}{E_{a \dot{a}}}$, where $T_{\delta 1}$ is the $E^{\prime \prime}$ peak temperature at the input frequency of $1 \mathrm{~Hz}$ and $E_{\mathrm{a} \delta}$ is the activation energy.

Table 3 Temperatures $\left({ }^{\circ} \mathrm{C}\right)$ extrapolated by Arrhenius and WLF models to a relaxation time of $100 \mathrm{~s}$ and glass transition temperatures reported in the literature

\begin{tabular}{|c|c|c|c|c|c|c|c|}
\hline \multirow[b]{2}{*}{ Solids } & \multirow{2}{*}{$\begin{array}{l}\text { Arrhenius } \\
\text { peak } E^{\prime \prime}\end{array}$} & \multirow[b]{2}{*}{$\mathbf{W L F}, \boldsymbol{T}_{\mathbf{g}^{\prime}}$} & \multirow{2}{*}{$\begin{array}{l}\text { Arrhenius } \\
\text { peak } \tan \delta\end{array}$} & \multicolumn{4}{|c|}{ Literature } \\
\hline & & & & Onset & Midpoint & Endset & $T_{m^{\prime}}$ \\
\hline Fructose & -53.2 & -52.9 & -43.1 & $-57^{2}$ & $-53^{2}$ & $\begin{array}{l}-50^{2} \\
-48^{13,14} \\
-43^{5} \\
-42^{1,7}\end{array}$ & $-46^{2}$ \\
\hline Glucose & -52.6 & -52.0 & -43.0 & $-57^{2}$ & $-53^{2}$ & $\begin{array}{l}-50^{2} \\
-44^{9} \\
-43^{7,10} \\
-40^{5}\end{array}$ & $-46^{2}$ \\
\hline Sucrose & -40.1 & -39.4 & -31.3 & $\begin{array}{l}-46^{2,8,16} \\
-49^{11,12}\end{array}$ & $-40^{2,8,13}$ & $\begin{array}{l}-37^{11} \\
-36^{2} \\
-35^{8,9,12} \\
-34^{1} \\
-32^{5,6,7,15}\end{array}$ & $-32^{2}$ \\
\hline Maltose & -34.2 & -34.0 & -26.3 & $-42^{2,3}$ & $\begin{array}{l}-37^{2} \\
-35^{3}\end{array}$ & $\begin{array}{l}-32^{1,2} \\
-31^{3} \\
-30^{7} \\
-29^{5}\end{array}$ & $\begin{array}{l}-32^{2} \\
-29^{3}\end{array}$ \\
\hline Lactose & -33.8 & -33.1 & -27.7 & $-41^{2}$ & $\begin{array}{l}-36^{2} \\
-33^{4}\end{array}$ & $\begin{array}{l}-30^{2} \\
-28^{7}\end{array}$ & $-30^{2}$ \\
\hline
\end{tabular}

Literature references: ${ }^{1}$ Kerr et al. (1993), ${ }^{2}$ Roos \& Karel (1995), ${ }^{3}$ Roos \& Karel (1991), ${ }^{4}$ Her et al. (1994), ${ }^{5}$ Wang \& Jane (1994), ${ }^{6}$ Schenz et al. (1993), ${ }^{7}$ Slade \& Levine (1991), ${ }^{8}$ Karel et al. (1994), ${ }^{9}$ Kerr \& Reid (1994), ${ }^{10}$ Maurice et al. (1991), ${ }^{11}$ Blond et al. (1997), ${ }^{12}$ Shalaev \& Franks (1995), ${ }^{13}$ Ablett et al. (1993a), ${ }^{14}$ Carrington et al. (1996), ${ }^{15}$ Levine \& Slade (1989), ${ }^{16}$ Roos (1995).

and $T_{\mathrm{g} i}$ and $T_{\mathrm{g} j}$ the glass transition temperatures of the pure sugars. It is noted that in the present case, as the sugars are mixed in equal parts, $x_{i}=x_{j}=(1-w) / 2$. A similar equation can be written for the quaternary solution.
Table 4 shows the values obtained. It can be seen that the $T_{\mathrm{g}}^{\prime}$ values experimentally determined for the sugar mixtures are very consistent with the literature data concerning the GordonTaylor equation for the binary sugar-water 
Table 4 Maximum cryo-concentrations estimated from the Gordon-Taylor equation $\left(T_{\mathrm{g}}^{\prime}\right.$ in ${ }^{\circ} \mathrm{C}, C_{\mathrm{g}}^{\prime}$ in weight percentage $\left.g_{\text {solids }} / 100 g_{\text {solids }+ \text { water }}\right)$

\begin{tabular}{|c|c|c|c|c|c|c|c|}
\hline \multirow[b]{2}{*}{ Sugar } & \multicolumn{4}{|c|}{ Binary sugar solutions } & \multicolumn{3}{|l|}{ Solutions of sugar mixtures } \\
\hline & $k^{(L)}$ & $T_{\mathrm{g}}^{(\mathrm{L})}$ (dry) & $T_{\mathbf{g}^{\prime}}^{(\exp )}$ & $C_{\mathrm{g}}^{(\mathrm{eq})}$ & Mixture & $T_{\mathbf{g}}^{\prime(\exp )}$ & $C_{\mathrm{g}}^{\prime(\mathrm{eq})}$ \\
\hline Fructose & $3.70^{1}$ & $16^{2}$ & -52.9 & 81.5 & Glucose $50 \%$-Fructose $50 \%$ & -51.4 & 81.1 \\
\hline Glucose & $4.52^{1}$ & $38^{3}$ & -52.0 & 80.7 & Glucose $50 \%$-Lactose $50 \%$ & -46.0 & 81.3 \\
\hline Sucrose & $5.42^{1}$ & $70^{3}$ & -39.4 & 82.6 & Fructose $50 \%$-Lactose $50 \%$ & -48.3 & 80.9 \\
\hline Maltose & $6.15^{1}$ & $95^{3}$ & -34.0 & 82.8 & Glucose $50 \%$-Maltose $50 \%$ & -46.2 & 81.0 \\
\hline Lactose & $6.56^{1}$ & $101^{4}$ & -33.1 & 83.3 & $\begin{array}{l}\text { Glucose } 33 \%-\text { Fructose } 33 \%- \\
\text { Lactose } 33 \%\end{array}$ & -51.9 & 79.7 \\
\hline
\end{tabular}

(L) Obtained from the literature (references indicated according to legend below);

${ }^{\text {(exp) }}$ Experimental (from the WLF equation for $\tau_{\mathrm{g}}=100 \mathrm{~s}$ );

(eq) Estimated from the Gordon-Taylor equation;

Literature references: ${ }^{1}$ Roos (1995), ${ }^{2}$ Simatos et al. (1996) (midpoint), ${ }^{3}$ Orford et al. (1990), ${ }^{4}$ Loyd et al. (1996).

matrices. Curiously, the $C_{\mathrm{g}}^{\prime}$ values obtained from equation (3) for the disaccharides are slightly higher. The $C_{\mathrm{g}}^{\prime}$ values of the ternary matrices differ by $<1-2 \%$ from the arithmetic average of $C_{\mathrm{g}}^{\prime}$ of the individual sugars used, while the quaternary solution shows a slightly larger deviation $(2.6 \%)$.

\section{Conclusions}

The $E^{\prime \prime}$ peaks from DMTA measurements show a frequency dependence that is coherent with their interpretation as a resonance point. By application of the WLF equation to data obtained at several frequencies, the values of $T_{\mathrm{g}}^{\prime}$ for several sugar solutions were obtained, being similar to literature values for the glass transition midpoint. The $\tan \delta$ peaks could also be related to the endset of the glass transition given in the literature. In both cases, this good agreement suggests average molecular relaxation times around $100 \mathrm{~s}$. The data for sugar mixtures were very consistent with the application of the Gordon-Taylor equation, indicating maximum cryo-concentrations around $80-83 \%$ for the various matrices studied. This suggests the adequacy of using the glass transition temperatures determined with the WLF equation (corresponding to the DSC midpoint) in quantitative analysis of the glass transition.

\section{Acknowledgments}

The authors would like to thank Nestlé for the financial support. Mr Pedro Pereira and Mr Jesus
Frias are also gratefully acknowledged for many useful discussions.

\section{References}

Ablett, S., Izzard, M.J., Lillford, P.J. \& Arvanitoyannis, I. (1993a). Calorimetric study of the glass transition occurring in fructose solutions. Carbohydrate Research, 246, $13-22$.

Ablett, S., Darke, A.H., Izzard, M.J. \& Lillford, P.J. (1993b). Studies of the glass transition in malto-oligomers. In: The Glassy State in Foods (edited by J. Blanshard \& P. Lillford). Pp. 189-206. Nottingham: UK Nottingham University Press.

Adam, G. \& Gibbs, J.H. (1965). Journal of Chemical Physics, 43, 139-146.

Allen, G. (1993). A history of the glassy state. In: The Glassy State in Foods (edited by J. Blanshard \& P. Lillford). Pp. 1-34. Nottingham: UK Nottingham University Press.

Angell, C.A., Monnerie, L. \& Torell, L.M. (1991). Strong and fragile behavior in liquid polymers. Materials Research Society Symposium Proceedings, 215, 3-9.

Angell, C.A., Bressel, R.D., Green, J.L., Kanno, H., Oguni, M. \& Sare, E.J. (1994). Liquid fragility and the glass transition in water and aqueous solutions. Journal of Food Engineering, 22, 115-142.

Blond, G., Simatos, D., Catté, M., Dussap, C.G. \& Gros, J.B. (1997). Modeling of the water-sucrose state diagram below $0^{\circ} \mathrm{C}$. Carbohydrate Research, 298, 139-145.

Carrington, A.K., Goff, H.D. \& Stanley, D.W. (1996). Structure and stability of the glassy state in rapidly cooled carbohydrate solutions. Food Research International, 29, 207-213.

Chan, R.K., Pathmanathan, K. \& Johari, G.P. (1986). Dielectric relaxations in the liquid and glassy states of glucose and its water mixtures. Journal of Physical Chemistry, 90, 6358-6362.

Cohen, M.H. \& Turnbull, D. (1959). Journal of Chemical Physics, 31, 1164-1169. 
Couchman, P.R. (1978). Compositional variation of glass transition temperatures. 2. Application of the thermodynamic theory to compatible polymer blends. Macromolecules, 11, 1156-1162.

Darby, R. (1975). Viscoelastic Fluids. Pp. 177-179. New York, USA: Marcel Dekker.

Doolittle, A. (1951). Studies in non-Newtonian flkow. II The dependence of the viscosity of liquids on free space. Journal of Applied Physics, 22, 1471-1478.

Ehrenfest, P. (1933). Proceedings of the Academy of Sciences of Amsterdam, 36: 153. Cited by Wundelich, B. (1981). The basis of thermal analysis. In: Thermal Characterisation of Polymeric Materials (edited by E. Turi). Pp. 91-112. New York, USA: Academic Press.

Frias, J., Oliveira, J.C., Cunha, L.M. \& Oliveira, F.A.R. (1998). Application of D-optimal design for determination of the influence of water content on the thermal degradation kinetics of ascorbic acid in dry environments. Journal of Food Engineering, 38, 69-85.

Gordon, M. \& Taylor, J. (1952). Ideal copolymers and the second order transitions of synthetic rubbers. I. Noncrystalline copolymers. Journal of Applied Chemistry, 2, 493-502.

Her, L., Jefferis, R.P., Gatlin, L.A., Braxton, B. \& Nail, S.L. (1994). Measurement of glass transition temperatures in freeze concentrated solutions of non-electrolytes by electrical thermal analysis. Pharmaceutical Research, 11, 1023-1029.

Karel, M., Anglea, S., Buera, P., Karmas, R., Levi, G. \& Roos, Y. (1994). Stability related transitions of amorphous foods. Thermochimica Acta, 246, 249-269.

Kerr, W. \& Reid, D.S. (1994). Temperature dependence of the viscosity of sugar and maltodextrin solutions in coexistence with ice. Lebensmittel Wissenschaft und Technologie (LWT-Food Science and Technology), 27, 225-231.

Kerr, W.L., Lim, M.H., Reid, D.S. \& Chen, H. (1993). Chemical reaction kinetics in relation to glass transition temperatures in frozen food polymer solutions. Journal of the Science of Food and Agriculture, 61, 51-56.

Levine, H. \& Slade, L. (1989). Thermomechanical properties of small carbohydrate - water glasses and 'rubbers': kinetically metastable systems at sub-zero temperatures. Journal of the Chemical Society, Faraday Transactions I, 84, 2619-2633.

Loyd, R.J., Chen, X.D. \& Hargreaves, J.B. (1996). Glass transition and caking of spray-dried lactose. International Journal of Food Science and Technology, 31, 305-311.

Luyben, W. (1990). Process Modelling, Simulation and Control for Chemical Engineers. Pp. 415-420. New York, USA: McGraw-Hill.

Mansfield, M. (1993). An overview of theories of the glass transition. In: The Glassy State in Foods (edited by J. Blanshard \& P. Lillford). Pp. 103-122. Nottingham: UK Nottingham University Press.

MacInnes, W.M. (1993). Dynamic mechanical thermal analysis of sucrose solutions. In: The Glassy State in
Foods (edited by J. Blanshard \& P. Lillford). Pp. 223-248. Nottingham: UK Nottingham University Press.

Maurice, T.J., Asher, Y.J. \& Thomson, S. (1991). Thermomechanical analysis of frozen aqueous systems. In: Water Relationships in Foods (edited by H. Levine \& L. Slade). Pp. 215-223. New York, USA: Plenum Press.

Moynihan, C.T., Balitaetac, N., Boone, L. \& Litovitz, T.A. (1971). Comparison of shear and conductivity relaxation times for concentrated lithium chloride solutions. Journal of Chemical Physics, 55, 3013-3018.

Narayanaswamy, O.S. (1971). A model of structural relaxation in glass. Journal of the American Ceramic Society, 54, 491-498.

Noel, T.D., Parker, R. \& Ring, S.G. (1996). A comparative study on the dielectric relaxation behaviour of glucose, maltose and their mixtures with water in the liquid and glassy states. Carbohydrate Research, 282, 193-206.

Orford, P.D., Parker, R. \& Ring, S.G. (1990). Aspects of the glass transition behavior of mixtures of carbohydrates of low molecular weight. Carbohydrate Research, 196, $11-18$.

Peleg, M. (1992). On the use of the WLF model in polymers and foods. Critical Reviews in Food Science and Nutrition, 32, 59-66.

Reid, D., Hsu, J. \& Kerr, W. (1993). Calorimetry. In: The Glassy State in Foods (edited by J. Blanshard \& P. Lillford). Pp. 123-132. Nottingham: UK Nottingham University Press.

Roos, Y. (1995). Phase Transitions in Foods. Pp. 113-115, 294. London: UK Academic Press.

Roos, Y. \& Karel, M. (1991). Water and molecular weight effects on glass transitions in amorphous carbohydrates and carbohydrate solutions. Journal of Food Science, 56(6), 1676-1680.

Roos, Y. \& Karel, M. (1993). Effects of glass transition on dynamic phenomena in sugar containing food systems. In: Glassy State in Foods (edited by J. Blanshard \& P. Lillford). Pp. 207-222. Nottingham: UK Nottingham University Press.

Roos, Y. \& Karel, M. (1995). Characterization of food polymers using state diagrams. Journal of Food Engineering, 24, 339-360.

Schenz, T.W., Courtney, K. \& Israel, B. (1993). Studies on the magnitude of the glass transition of glucose polymers. Cryo-letter, 14, 91-96.

Scherer, G.W. (1991). Glass formation and relaxation. In: Materials Science and Technology-A Comprehensive Treatment, vol. 9 -Glasses and Amorphous Materials (edited by J. Zarzycki). Pp. 120-173. Weinheim, Germany: VCH Publications.

Shalaev, E.Y. \& Franks, F. (1995). Structural glass transitions and thermophysical processes in amorphous carbohydrates and their supersaturated solutions. Journal of the Chemical Society, Faraday Transactions, 91, 1511-1517.

Simatos, D., Blond, G., Roudaut, G., Champion, D., Perez, J. \& Faivre, A.L. (1996). Influence of heating and cooling rates on the glass transition temperature and the fragility 
parameter of sorbitol and fructose as measured by DSC. Journal of Thermal Analysis, 47, 1419-1436.

Slade, L. \& Levine, H. (1991). A polymer science approach to structure/property relationships in aqueous food systems: non-equilibrium behavior of carbohydrate-water systems. In: Water Relationships in Foods (edited by H. Levine \& L. Slade). Pp. 29-101. New York, USA: Plenum Press.

Slade, L. \& Levine, H. (1993). The glassy state phenomenon in food molecules. In: The Glassy State in Foods (edited by J. Blanshard \& P. Lillford). Pp. 35-102. Nottingham: UK Nottingham University Press.
Slade, L. \& Levine, H. (1995). Glass transitions and waterfood structure interactions. Advances in Food and Nutrition Research, 38, 103-269.

Wang, Y.-J. \& Jane, J. (1994). Correlation between glass transition temperatures and starch retrogradation in the presence of sugars and maltodextrins. Cereal Chemistry, 71, 527-531.

Williams, M., Landel, R. \& Ferry, J. (1955). The temperature dependence of relaxation mechanisms in amorphous polymers and other glass-forming liquids. Journal of the American Chemical Society, 77, 3701-3706. 